\title{
Gender and Phenotype Differences in Spirituality in Adults Coping with Sickle Cell Disease in Ghana: Preliminary Findings
}

\author{
*Michael Tetteh Anim \\ Department of Psychological Medicine and Mental Health, University of Cape Coast, North Africa
}

Submission: December 16, 2017; Published: January 05, 2018

*Corresponding author: Michael Tetteh Anim, Department of Psychological Medicine and Mental Health, Office Suite 1, School of Medical Sciences, College of Health and Allied Sciences, University of Cape Coast, P.M.B, Cape Coast, Ghana, North Africa; Tel: +233 277705172;

Email: manim@ucc.edu.gh

\begin{abstract}
The research examined the level of spirituality, and gender and phenotype differences in spirituality among participants with sickle cell disease (SCD) in Ghana. Most recent research among different patient and healthy samples show that women are more spiritual and religious and thus cope better with chronic disease than men. However, researchers neglected to study these factors in SCD. In this study, a survey was administered to a purposive sample of 201 Ghanaian adults with SCD to assess their level of spirituality. The Spiritual Wellbeing Scale was used to measure their spirituality. The study results showed a moderate level of spirituality. Majority of participants attested to their use of spirituality in coping with SCD. However, there was lack of evidence of a statistically significant difference between men and women, and between hemoglobin SS and hemoglobin SC participants on the spirituality test scores. This lack of statistical significance, however, did not imply lack of research, theoretical, and practical significance too. The findings make us know that, given the chronicity of the SCD, the condition does not necessarily make sickle cell individuals highly spiritual as expected. We also conclude that participants coped with SCD using some form of spirituality. However, gender and phenotype differences did not contribute significantly to the way individuals with SCD might be expected to use spirituality in their lives. To the extent that this current result revealed exactly the degree, and differential experiences of spirituality between male and female and hemoglobin SS and hemoglobin SC phenotypes, it is an addition to previous research. The implications of the findings for cultural coping with SCD, spiritual training for patients, and further research to explore other cultural coping strategies for these Ghanaians with the condition, have been discussed.
\end{abstract}

Keywords: Sickle cell disease, spirituality, religion, gender, phenotype, coping, Ghana

\section{Introduction}

Sickle cell disease (SCD) is a hemoglobinopathy that is genetically inherited El-Hazni [1]; Konotey-Ahulu 1991. The disease presentation and patient response patterns are variable Neville [2]. The disease is categorized genotypically according to the predominance of hemoglobin $\mathrm{S}$, taking on forms such as hemoglobin SS, hemoglobin SC, beta thalassemia, with clinical symptoms ranging from an asymptomatic course to a debilitating disease with increased mortality Firth, Head [3]. Acute unpredictable and intermittent crises and chronic endorgan damage are some other complications. In the recent past, these complications have led to early deaths among this population. However, beginning from the 1970s, improved medical care for these patients have led to long life although SCD individuals often have shortened lifespan compared with the general population Platt [4]. Individuals with SCD have an unpredictable course that can range from mild to severe disease that reduces quality of life, causes frequent hospitalizations, and results in physical limitations, psychological and social problems NIH [5].

How SCD affects the physical, psychological and social aspects of patient life are known in some detail Anie [6]; Caird [7]. However, how SCD affects the spiritual dimensions of the patient is not vastly researched. The way SCD and its stresses are highly variable, so are the ways of coping with the physical, psychological and social complications of the disease Caird [7]. SCD individuals cope with the disease in a variety of ways, such as medical, psychological counseling, behavior modification, family support, drug use and abuse, hypnosis, herbal medication, and prayer. While most of these coping strategies are based in psychological strategies Jonassaint [8], others are based in complementary and alternative medicine Wachholtz, Pearce [9].

Spirituality and religiosity are other ways of coping with a variety of diseases. They both play a role in the spiritual wellbeing of an individual. Ellison [10] described spiritual 
wellbeing as a two-fold state. It includes a religious component, a positive specific relationship with God, and a spiritual or existential component that involves a sense of life purpose and satisfaction. A positive relationship between spiritual wellbeing and psychological wellbeing exist. An inverse relationship between existential wellbeing and depression also exists. A direct association of spirituality and hope it also exists Landis. Spirituality can therefore reduce depression, anxiety, and hopelessness/helplessness and can promote better psychological health Hays.

Although regarded as important in the life process, there has been little emphasis on spirituality in medical practice CooperEffa et al. [11]. The effect of spirituality on disease outcomes has however, been documented as being largely positive Koenig [12]. Research found that spiritual health positively affects physical energy and improves health Koenig [12]. A positive correlation of lower blood pressure and church attendance has been documented Larson [13]. Religious faith helped elective cardiac surgery patients to survive. There is a positive influence of prayer for patients in a coronary unit Byrd [14]; Oxman [15].

In the United States, sickle cell disease is found predominantly among the African American population. This population has traditionally regarded religion as an important aspect of their lives Lincoln, Mamiya. African Americans are frequent church goers and have a high probability of being church members Taylor. The same is true about many Africans, West Africans and Ghanaians Assimeng [16]; Gyekye [17] among whom SCD is also highly prevalent.

Although investigated in other diseases including SCD in the West, Europe and Asia, and some parts of Africa, spirituality has not been widely evaluated in SCD individuals in Ghana yet. Again, although spirituality has been reported among SCD participants in previous studies Cooper-Effa et al. [11]; Harrison et al. [18], details about gender and disease type differences in the experience of spirituality have not been documented, except on gender differences in sickle cell crisis Ilesanmi [19].

Few gender differences in spirituality have been documented, but not in reference to sickle cell disease. For example, Byrant [20] surveyed a representative sample of freshmen in 434 colleges and universities in the USA. After three years, Byrant surveyed a subset of the initial sample to determine the effect of college life on students' spirituality. Byrant's [20] results demonstrated that women scored higher than men on religiosity. The difference between women and men on religious practice (22\% versus $18 \%$ respectively) was smaller than it was on religious belief (35\% and $27 \%$, respectively). Women had higher spirituality scores than men. Similarly, Hammermeister et al. [21] surveyed 435 college students with the Spiritual Well-Being Scale. They found females to have scored higher than males on all three indices of spiritual wellbeing, religious wellbeing and existential wellbeing. Based on this finding, Hammermeister et al. [21] recommended that men should be targeted for greater spiritual exposure at universities and learning centers.
Another study on gender differences in spirituality that yielded similar results as the above was that conducted by Buchko [22] in a single university in the USA among European Americans. She found that women reported more prayer and meditation time than men did, sensed more of God's activity and presence in day-to-day life, and reported more feelings of devotion and reverence than men. Although Buchko's [22] findings may not apply to other racial groups and nationalities, it hints on some differences that could exist between men and women in their spiritual experiences.

A research report that challenged previous findings mentioned above is that of Simpson, Cloud, Newman, and Fuqa who surveyed 250 church-goers and religious school staff in the USA. This sample completed the Spiritual Wellbeing Scale together with other spirituality and religiosity measures. This study found no significant difference between men and women in religious participation and in relationship with God, thus calling into question the assumption that women are more religious or spiritual than men. These results, however, cannot be generalized beyond religious circles and college educated samples. With this apparent contradiction of results, what would the picture look like for chronic disease individuals with SCD who attend the sickle cell clinic in Korle-Bu Teaching Hospital, Ghana? The researcher based the study on the biopsychosocialspiritual paradigm posited by Hiatt [23]. This model adds a spiritual dimension to Engel's biopsychosocial model, there by connecting mind, body and spirit to reflect the multi-faceted nature of the individual.

Based on the above-mentioned theoretical model, it was the objective of this present study to assess the level of spirituality, to determine differences among males and females, and HbSS and HbSC participants on spirituality scores. This study reports an assessment of the level and presence of spirituality in adults coping with the medical, psychological and social complications of SCD in Ghana. The study reports the answers to the research question: What is the level of spirituality among participants with SCD? It also tests the exploratory hypothesis that there would be a statistically significant difference between males and females as well as between HbSS and HbSC participants in their report of the helpfulness of spirituality in coping with SCD, with female SCD participants and HbSS participants assenting more to spirituality's helpfulness than their counterparts, respectively. Finally, the study tested the hypotheses that females would score higher on spirituality than male SCD participants; and HbSS participants would score higher on spirituality than HbSC participants.

\section{Methods}

\section{Study Design}

A descriptive cross-sectional design was used to assess spirituality and its helpfulness in coping with SCD.

\section{Participants/sampling}

Adults 18 years and above who suffered from HbSS and HbSC 
forms of sickle cell disorder, and who could read and understand English, who were not in crisis, and consented to participate in a preliminary survey research, were purposively sampled $(\mathrm{n}=$ 201) from the Korle-Bu Teaching Hospital's sickle cell clinic in Accra, Ghana.

They were engaged after obtaining clearance and written permission from the Director of the Institute of Clinical Genetics, Korle-Bu Teaching Hospital, Accra, Ghana, and also after obtaining written informed consent from potential participants and explaining the purpose of the study to them. The study comprised of 102 males (51\%) and 99 females (49\%) with HbSS genotype (65\%) and HbSC genotype (39\%).

\section{Measures}

To measure respondents opinion about the helpfulness of spirituality in coping with SCD, the question, «Do you think spirituality helps in coping with SCD?» was posed and respondents had to indicate a 'yes' or a 'no' response. The Spiritual Wellbeing Scale Paloutzian, Ellison [24] was used to measure spirituality. The instrument is a 20 -item questionnaire with responses based on a six-point Likert scales, ranging from strongly agree to strongly disagree. The questionnaire is divided into two subscales: 10 items focus on life satisfaction and life direction (existential wellbeing), and 10 items focus on belief in God (religious wellbeing). Spiritual wellbeing was measured using scores from both subscales.

The Spiritual Wellbeing score is a measure of perceived overall wellbeing. Each SWBS item is scored from 1 to 6, with a higher number representing greater wellbeing. Negatively worded items are reversed scored. To obtain total score for spiritual wellbeing, the scores for the positively and negatively worded items are totaled. A score in the range of 20 to 40 reflects a sense of low overall spiritual wellbeing. A score in the range of 41 to 99 reflects a sense of moderate spiritual wellbeing. A score in the range of 100 to 120 reflects a sense of high spiritual wellbeing. The Religious Wellbeing Score is a measure of how one views their relationship with God. It reflects one's sense of satisfaction and positive connection with God. A score in the range of 10 to 20 reflects a sense of unsatisfactory relationship with God. A score in the range of 21 to 49 reflects a moderate sense of religious wellbeing. A score in the range of 50 to 60 reflects a positive view of one's relationship with God. The Existential Wellbeing score measures one's level of life satisfaction and life purpose. A score in the range of 10 to 20 suggests a low satisfaction with one's life and possible lack of clarity about one's purpose in life. A score in the range of 21 to 49 suggests a moderate level of life satisfaction and purpose. A score in the range of 50 to 60 suggests a high level of life satisfaction with one's life and a clear sense of purpose.

Cronbach's alpha coefficients reflecting internal consistency were 0.89 (SWB), 0.87 (RWB) and 0.78 (EWB). The test-retest reliability coefficients were 0.93 (SWB), 0.96 (RWB) and 0.86 (EWB). These are consistent with high reliability and internal consistency. In the current study, the Cronbach's alpha coefficient was .77. This value was above .7, so the scale was considered reliable with our sample. The SWB scale appears to have sufficient validity for use as a quality of life indicator. SWB scores correlated in predicted ways with several other scales. People who scored high on SWB tended to be less lonely, more socially skilled, high in self-esteem and more intrinsic in their religious commitment. The SWB, RWB, and EWB all correlated positively with the Purpose in Life Test. The scale has been used to assess the relationship between loneliness and spiritual wellbeing in a college population as well as used to assess spiritual well-being in chronically-ill adults.

\section{Procedure}

From January to September, 2013, SCD participants 18 years and older attending the sickle cell clinic at the Korle-Bu Teaching Hospital in Accra, Ghana, were asked to complete a questionnaire that elicited information on demographics, disease characteristics, and spirituality. SCD participants were contacted in person by the principal researcher and/or his assistant. Questionnaires were completed at the clinic during the patients review visits and at a time when the patient was not in pain crisis after both verbal and written informed consents were obtained. A pastry and soft drink were offered participants for the time required to complete the questionnaire. Two hundred and one (201) SCD participants out of about 250 who were contacted participated. Medical records were reviewed to confirm sickle cell type and severity.

\section{Data analysis}

Frequencies and chi square tests were used to assess the level of spirituality and reported use of spiritual coping with SCD among the participants. Chi square test is the recommended method of evaluating the relationship between one categorical independent variable and one categorical dependent variable Ofori, Dampson [25]; Pallant [26]. The t-test is the recommended analysis to evaluate the difference between two categorical groups on a continuous variable.

\section{Results}

Table 1: Demographic and Disease Characteristics of Sample.

\begin{tabular}{|c|c|c|}
\hline Demographic variables (n = 201) & Frequency & $\begin{array}{c}\text { Percentage } \\
\text { (\%) }\end{array}$ \\
\hline Sex & & \\
\hline Male & 102 & 50.7 \\
\hline Female & 99 & 49.3 \\
\hline Sickle cell type & & \\
\hline SS & 131 & 65.2 \\
\hline SC & 70 & 34.8 \\
\hline $\begin{array}{c}\text { Does spirituality help to cope with } \\
\text { SCD }\end{array}$ & 153 & 76.1 \\
\hline Yes & 48 & 23.9 \\
\hline No & & \\
\hline
\end{tabular}




\section{Psychology and Behavioral Science International Journal}

\begin{tabular}{|c|c|c|}
\hline Spiritual Well-Being (SWB) Score & & \\
\hline Low & 2 & 1 \\
\hline Moderate & 195 & 97 \\
\hline High & 4 & 2 \\
\hline
\end{tabular}

Tables $1 \& 2$ are used to summarize the key findings of the study. To answer the first research question about the level of spirituality among SCD participants, frequencies and percentages were calculated. Table 1 shows that almost equal proportion of males and females took part in the study, while more participants with HbSS than HbSC took part. The overwhelming majority (76\%) indicated that spirituality helps to cope with sickle cell disease. While the majority (97\%) had a moderate score on spirituality, few (2\%) scored high and very few (1\%) scored low on spirituality (Table 1).

Table 2: Results of Chi-Square Test Showing Relationship between Sex and Using Spirituality to Cope and Sickle Cell Type and Using Spirituality to Cope with SCD.

\begin{tabular}{|c|c|c|c|c|c|}
\hline Variable & $\begin{array}{c}\text { Spirituality } \\
\text { Helps }\end{array}$ & & & & \\
\hline & Yes & No & & & \\
\hline & Frequency & Frequency & $d f$ & $\chi^{2}$ & $\rho$ \\
\hline \multicolumn{6}{|l|}{ Male } \\
\hline $\begin{array}{c}\text { Observed } \\
\text { Count }\end{array}$ & 75 & 27 & & & \\
\hline $\begin{array}{l}\text { Expected } \\
\text { Count }\end{array}$ & 77.6 & 24.4 & & & \\
\hline Female & & & 1 & .764 & .382 \\
\hline $\begin{array}{c}\text { Observed } \\
\text { Count }\end{array}$ & 78 & 21 & & & \\
\hline $\begin{array}{l}\text { Expected } \\
\text { Count }\end{array}$ & 75.4 & 23.6 & & & \\
\hline \multicolumn{6}{|l|}{ HbSS } \\
\hline $\begin{array}{c}\text { Observed } \\
\text { Count }\end{array}$ & 103 & 28 & & & \\
\hline $\begin{array}{l}\text { Expected } \\
\text { Count }\end{array}$ & 99.7 & 31.3 & & & \\
\hline HbSC & & & 1 & 1.300 & .254 \\
\hline $\begin{array}{c}\text { Observed } \\
\text { Count }\end{array}$ & 50 & 20 & & & \\
\hline $\begin{array}{l}\text { Expected } \\
\text { Count }\end{array}$ & 53.3 & 16.7 & & & \\
\hline
\end{tabular}

\section{Exploratory Hypothesis 1}

The chi-square test was used to investigate whether there was an association between participants' sex and their reported use of spirituality to cope with SCD. It was hypothesized that females would report a statistically significant greater use of spirituality in coping than males. The investigation involved a $2 \times 2$ design where sex was measured on two levels (males and females) and report on using spirituality was measured on two levels (yes and no). Table 2 presents the $2 \times 2$ contingency table showing the actual and expected counts. For sex, 75 male participants were observed as reporting that spirituality helps to cope with SCD but more (i.e., 77.6) were expected to report "yes", spirituality helps in coping; whereas among female participants, 78 were observed as having affirmed that spirituality helps but less, (i.e. 75.4) were expected to affirm. It was expected that more females would report that spirituality is helpful to cope than males would report. Although the expectation for males was more than for females, the observed or actual report indicated that more females (78) reported the helpfulness of spirituality in coping than males actually reported (75) (Table 2). The chi-square test performed to ascertain whether these differences were enough to be significant revealed that there was no statistically significant difference in the report of spirituality's helpfulness in coping with SCD between males and females $(\chi 2=.764 ; \mathrm{df}=1$; p> .05) (Table 2).

\section{Exploratory Hypothesis 2}

Similarly, the chi-square test was used to investigate whether there was an association between participants' disease type and their reported use of spirituality to cope with SCD. It was hypothesized that HbSS participants would report a statistically significant greater use of spirituality than HbSC participants. The investigation involved a $2 \times 2$ design where sickle cell type was measured on two levels (HbSS and HbSC) and report on using spirituality was measured on two levels (yes and no). Table 2 presents the $2 \times 2$ contingency table showing the actual and expected counts. For HbSS, 103 participants were observed as reporting that spirituality helps to cope with SCD but less (i.e., 99.7) were expected to report "yes", spirituality helps in coping; whereas among HbSC participants, 50 were observed as having affirmed that spirituality helps but more, (i.e. 53.3) were expected to affirm. It was expected that more HbSS participants would report that spirituality was helpful to cope than HbSC participants would report. The expectation for HbSS participants (99.7) was more than that for HbSC (53.3), and the observed or actual report indicated that more HbSS (103) reported the helpfulness of spirituality in coping than $\mathrm{HbSC}$ actually reported (50). The chi-square test performed to ascertain whether these differences were enough to be significant revealed that there was no statistically significant difference in the report of spirituality's helpfulness in coping with SCD between HbSS and HbSC participants $(\chi 2=.1 .300 ; \mathrm{df}=1 ; \mathrm{p}>.05)$.

\section{Discussion}

It was the specific objective of the study to determine the level of spirituality among adults with SCD. The results showed that majority of SCD participants had moderate spirituality, only few had high spirituality and almost none had low spirituality. While this result is similar and throws some more light on previous findings by specifying the exact level or degree of spirituality in SCD participants, it was expected that the majority would rather report high spirituality. Previous research disclose that SCD participants used spirituality to cope with SCD CooperEffa et al. [11]; Harrison et al. [18], but did not specify how much. To the extent that this current result revealed exactly the degree of spirituality SCD participants had, it is an addition to previous research. 
The current result fails to agree with researchers and scholars such as Assimeng [16]; Belgrave and Allison [27], Gyekye [17], Mibiti [28]; Nobles [29]; Utsey [30], who believe that the African is highly spiritual. Given that most of these scholars asserted this in the context of healthy populations, it is probable that chronic disease individuals like these SCD participants have different, probably lowered degree of spirituality compared with healthy individuals. Cotton et al. [31] studied spirituality in patients with SCD and concluded that spiritual wellbeing could help patients cope more effectively with sickle cell pain. This effect, however, appears to be through a perception of more life control measured through the perception of social support. Considering oneself to be spiritual was correlated with perceiving oneself to have a supportive network. Their study showed the importance of spiritual wellbeing in coping with the complications of SCD. But they did not determine exactly how much of spiritual wellbeing caused this effect. Existential wellbeing (a component of spiritual wellbeing) was associated with general coping ability. The effect of religious wellbeing on coping was not so strong.

This study, however, looked specifically at the degree of spirituality in SCD participants. It did not however, attempt to examine the association of spirituality with coping ability in SCD. This is the difference between this and previous research. This study did not look at specific spiritual activities among SCD participants, such as prayer, religious attendance, meditation, and scripture reading. Previous research with musculoskeletal and arthritis patients did and found prayer to be the most common complementary therapy used by such patients Wachholtz, Pearce [9].

It was another specific objective of the study to examine differences between males and females in their reported use of spiritual coping with SCD. The results showed that although more females reported the helpfulness of spirituality in coping than males reported, the difference lacked statistical significance. This did not imply that the difference lacked practical significance. To the best of the researcher's knowledge, this is the first documented research report on male-female differences in reported use of spirituality in coping with SCD. How this translates into actual coping with psychological symptoms and/ or pain in sickle cell was not examined by this study. However, previous researches as indicated above demonstrated that individuals with SCD in general use spirituality to cope.

A possible reason why females reported using spirituality to cope more than males is that it has been widely accepted that females are more likely to be religious than males Hammermeister et al. [21]. Three major explanations have been given. The first explanation is that women feel emotions at greater heights than men do, and so women turn to religion more in times of high emotions such as gratitude or guilt Durik et al. [32]. The second explanation is that female socialization is more likely to support values that are commonly found in religion such as conflict negotiation, sensitivity, and humility. In contrast, male socialization is more likely to emphasize rebellion, thus making the restrictive aspects of religion less attractive. The third explanation, which is also the most recent theory, is that females are more likely to be able to identify with religion as a natural consequence of societal structures. Since the majority of religions emphasize women as caretakers of the home, the societal expectation of women to take greater responsibility than men for the upbringing of a child makes religion an appealing commitment. Traditionally, men tend to work outside the home whereas women tend to work inside the home, which corresponds to studies that have shown that people are more likely to be religious when working inside of their homes Krause [33]. This religious disposition is likely carried into experiences with chronic disease like sickle cell.

Hammermeister et al. [21] obtained similar results and reached similar conclusions concerning gender and spirituality as the present study. However, their sample was different from the current study sample. They administered a survey to 435 college students enrolled in health and fitness classes, and the survey included the Spiritual Wellbeing Scale. Females scored higher than males on all three spiritual indices of spirituality measured by the SWBS. Based on this result, Hammermeister et al. [21] recommended that men should be targeted for greater spiritual exposure at universities, places of learning, and health centers. Sex and religiosity or spirituality may have correlation. However, Simpson [34] considers that the relationship is actually between gender orientation and religiosity. It means that differences in spirituality or religiosity depend on how masculine or feminine a person is. According to Stokes (1990), women are more likely to describe religion as a relationship with God, while men view religion as a set of beliefs.

Finally, the present result is similar in findings to Rich's [35] result and to Simpson [33] finding. Rich [35] conveniently sampled 399 university students to assess their level of spirituality and found virtually no significant difference between men and women's scores on the spirituality test. They studied 250 churchgoers and religious school staff from a southeastern and southwestern state. These participants completed several spirituality measures including the Spiritual Wellbeing Scale, and contrary to several previous researches, their study found no significant difference between men and women in religious participation. But the present study is different from Simpson [33] in the sense that their population is different, is not sickle cell population. They found no significant difference between men and women in the level of involvement in religious activities, church attendance, private or personal acts of religiosity or in relationship with God.

Such previous results and the current finding call into question the belief that women are more spiritual or religious than men. They also dispute the notion that there are spiritual differences between gender orientations. Again, the present and previous studies cannot be compared because their samples were mostly university and college-educated samples whereas the current study's sample is educated chronic disease, sickle cell patients [36]. 
The finding of the current study is limited in generalizability to SCD participants. The results may not necessarily apply to males and females of different age groups and education levels, and disease conditions or health status. It was the third objective of this study to examine differences between participants with $\mathrm{HbSS}$ and HbSC in their reported use of spirituality to cope with SCD. The results indicated lack of evidence of a statistically significant difference between HbSS and HbSC participants on spirituality, in spite of a higher mean for HbSS over HbSC. While this is a statistical non-significant difference, the results implied a theoretical and practically significant difference between HbSS and HbSC participants. The non-significant result appeared to imply that disease type and severity did not affect degree of spirituality. However, by the practical difference in their mean values, disease type and severity do affect spirituality. It is not known whether the participants used spirituality to cope with SCD since the research did not explore that relationship [35].

\section{Limitations and Future Research}

The study did not examine specific spiritual activities among SCD participants. It is possible that there is variability in the degree of specific spirituality elements. The study did not examine the subscales of the Spiritual Wellbeing Scale to ascertain participants' performance on them. It is recommended that future research addresses these limitations. Future research should examine the association between spirituality and coping with SCD, especially across gender and disease types. The scale that measured spirituality, although had good internal reliability; its validity was not ascertained. If the scale was not valid, it could affect the results and its interpretation and practical use. It is recommended for future research to determine the validity of the spirituality measure used to assure its cultural validity or suitability.

\section{Conclusion}

Spirituality was not high, but moderate, among participants. Differences between male and female SCD individuals and HbSS and HbSC individuals in spirituality may lack evidence of statistical significance, but may demonstrate theoretical and practical significance that can be explored further in either longitudinal, prospective, or qualitative studies. Spirituality may contribute to coping with sickle cell disease in Ghana.

\section{Implications of the findings and Contribution to literature}

As an addition to the literature on the subject, this study contributes some understanding of spirituality and the influence of gender on spirituality, especially in the context of chronic disease. The influence of gender on spirituality is not calculated by statistical significance alone, but also by practical significance. Since ninety-four percent of the present SCD study sample is Christian and six percent is Muslim, suggesting that the sample is religious, this understanding may influence how individuals see their spirituality and how religious organizations who promote spirituality should tailor their services to the needs of SCD men and women. It could be that SCD men and women do not differ in levels of spirituality but in ways of expressing spirituality. The results will help further studies to determine whether men may be more action oriented in their spirituality and females may be more relationship and emotion oriented in their spirituality, and that's why females appear to be more spiritual than men in this study and many earlier ones. This finding is relevant to clinical practice. It contributes knowledge to health care professionals, particularly doctors and nurses, about the role of spirituality in adult patients' coping with sickle cell disease. Hopefully, the research will be useful to clinicians and nurse educators as they strive to incorporate spiritual care into their practice. In turn patients and their families should benefit from care that is allinclusive and addresses their deepest spiritual concerns and needs. There is a lot of future research to be done in the area of gender and spirituality. This research could be administered to samples of other specific chronic disease populations for comparison. It is also recommended for further research the exploration of the relationship between genotype and spiritual or religious coping with sickle cell disease.

\section{Acknowledgment}

The author is indebted to the University of Cape Coast who sponsored the $\mathrm{PhD}$ research out of which came this preliminary results. The researcher acknowledges and commends adults with SCD in the sickle cell clinic of the Korle-Bu Teaching Hospital, Accra, Ghana for their participation and sharing of information. He thanks the administrator, nurses, and doctors of the clinic who cooperated in data collection. He further thanks the research assistants who helped to collect the preliminary data.

\section{References}

1. El-Hazni MAF, Al-Hazni AM, Warsy AS (2011) Sickle cell disease in the Middle East Arab countries. Indian Journal of Medical Research 134(5): 597-610.

2. Neville KA, Panepinto JA (2011) Pharmacotherapy of sickle Cell Disease. $18^{\text {th }}$ Expert Committee on the Selection and use of Essential Medicines.

3. Firth PG, Head CA (2004) Sickle Cell Disease and Anesthesia. Anesthesiology 101: 766-785.

4. Platt OS, Brambilla DJ, Rosse WF (1991) Mortality in sickle cell disease. Life expectancy and risk factors for early death. N Engl J Med 330: 1639-1644.

5. National Institute of Health (2002) The Management of Sickle Cell Disease, $4^{\text {th }}$ edn.

6. Anie KA (2005) Psychological complications in sickle cell disease. British Journal of Haematology 129(6): 723-729.

7. Caird H, Camic PM, Thomas V (2011) The lives of adults over 30 living with sickle cell disorder. British Journal of Health Psychology 16: 542558.

8. Jonassaint CR, Jonassaint JC, Stanton WV, DeCastro LM, Royal CD (2010) Clinical and Sociodemographic Factors Predict Coping Styles Among Adults with Sickle Cell Disease. Journal of the National Medical Association 102(11): 1045-1049. 
9. Wachholtz AB, Pearce MJ (2009) Does spirituality as a coping mechanism help or hinder coping with chronic pain? Current Pain and Headache Reports 13(2):127-132.

10. Ellison CW (1983) Spiritual well-being: Conceptualization and measurement. Journal of Psychology and Theology 11: 330-340.

11. Cooper-Effa M, Blount W, Kaslow N, Rotenberg R, Eckman J (2001) Role of Spirituality in Patients with Sickle Cell Disease. J Am Board Fam Pract 14(2): 116-122.

12. Koenig HG (2008) Medicine, religion, and Health. Templeton Foundation Press, Pennsylvania, USA.

13. Larson DB, Koenig HG, Kaplan, BH, Greenberg RS, Logue E, et al. (1989) The impact of religion on men's blood pressure. Journal of Religion and Health 28(4): 265-278.

14. Byrd RC (1988) Positive Therapeutic Effects of Intercessory Prayer in a Coronary Care Unit Population. Southern Medical Journal 81(7): 826829

15. Oxman TE, Freeman DH, Manheimer ED (1995) Lack of social participation or religious strength and comfort as risk factors for death after cardiac surgery in the elderly. Psychosomatic Medicine 57(1) 5-15.

16. Assimeng M (2010) Religion and Social Change in West Africa (2 ${ }^{\text {nd }}$ edn.). Woeli Publication Services, Accra, West Africa.

17. Gyekye K (1996) African Cultural Values: An Introduction. Sankofa Publishing Company, Accra, West Africa.

18. Harrison MO, Edwards CL, Koenig HG, Bosworth HB, Decastro L, et al. (2005) Religiosity/Spirituality and Pain in Patients with Sickle Cell Disease. Journal of Nervous and Mental Disease 193(4): 250-257.

19. Ilesamni 00 (2013) Gender Differences in Sickle Cell Crises: Implications for Genetic Counselling and Psychotherapy. J Psychol Psychotherapy 3(4): 1-11.

20. Bryant AN (2007) Gender differences in spiritual development during the college years. Sex Roles, 56(12): 835-846.

21. Hammermeister J, Flint M, El-Alayli A, Ridnour H, Peterson M (2005) Gender differences in spiritual well-being: Are females more spiritually-well than males? American Journal of Health Studies 20(2): 80-84.

22. Buchko KJ (2004) Religious beliefs and practices of college women as compared to college men. Journal of College Student Development 45(1): 89-98.
23. Hiatt JF (1986) Spirituality, Medicine, and Healing. Southern Medical Journal 79(6): 736-743.

24. Paloutzian RF, Ellison CW (1982) Loneliness, spiritual well-being and quality of life. In LA Peplau, D Perlman (Eds.). Loneliness: A sourcebook of current theory, research and therapy, John Wiley and Sons publishing Company, New York, USA.

25. Ofori R, Dampson DG (2011) Research Methods and Statistics Using SPSS. Payles Publications Limited, Amakom, Ghana.

26. Pallant J (2010) SPSS Survival Manual (4th edn.). Allen \& Unwin Book Publishers, Australia.

27. Belgrave FZ, Allison KW (2006) African American Psychology: From Africa to America, Sage Publications, London.

28. Mbiti JS (1975) African Religions and Philosophy. Doubleday Anchor Books, Garden City, New York, USA.

29. Nobles WW (2006) Seeking the Sakhu: Foundational Writings for an African Psychology. The Third World Press, Chicago, USA.

30. Utsey SO (1999) Development and validation of a short version of the index of Race-Related Stress (IRRS-Brief Version) Measurement and Evaluation in Counselling and Development 32: 149-197.

31. Cotton S, Grossoehme D, Rosenthal SL, Mc Grady ME, Roberts YH, et al. (2009) Religious/spiritual coping in Adolescents with sickle cell disease: A Pilot Study. J Pediatr Hematol Oncol 31(5): 313-318.

32. Durik AM, Hyde JS, Marks AC, Roy AL, Anaya D, et al. (2006) Ethnicity and gender stereotypes of emotion. Sex Roles 54(7): 429-445.

33. Krause N, Ellison CG, Marcum JP (2002) The effects of church-based emotional support on health: Do they vary by gender? Sociology of Religion 63(1): 21-47.

34. Simpson DB, Cloud DS, Newman JL, Fuqua DR (2008) Sex and gender differences in religiousness and spirituality. Journal of Psychology and Theology 36(1): 42-52

35. Rich A (2012) Gender and Spirituality: Are Women Really More Spiritual? A Senior Thesis submitted in partial fulfillment of the requirements for graduation in the Honors Program, Liberty University, Spring

36. Stokes K (1990) Faith development in the adult life cycle. Journal of Religious Gerontology 7: 167-184.

Your next submission with Juniper Publishers will reach you the below assets

- Quality Editorial service

- Swift Peer Review

- Reprints availability

- E-prints Service

- Manuscript Podcast for convenient understanding

- Global attainment for your research

- Manuscript accessibility in different formats

( Pdf, E-pub, Full Text, Audio)

- Unceasing customer service

Track the below URL for one-step submission https://juniperpublishers.com/online-submission.php 